\title{
REPRESENTASI IDOLA FILM ANIMASI SHINGEKI NO KYOJIN PADA TOKOH LEVI DAN MIKASA
}

\author{
Endah Riana Endarini \\ Program Pascasarjana Program Studi Magister Desain \\ Universitas Komputer Indonesia \\ Jl. Dago (Ir. H. Djuanda) 160-162, Bandung, 40132 \\ e-mail: riana.endarini@gmail.com \\ $\begin{array}{llll}\text { Received: } \mathrm{n} / \mathrm{a} & \text { Revised: } \mathrm{n} / \mathrm{a} & \text { Accepted: } \mathrm{n} / \mathrm{a} & \text { Published: 2019-09-16 } \\ \text { Editor: Abay D Subarna } & \text { Reviewer: } \mathrm{n} / \mathrm{a} & & \end{array}$
}

\begin{abstract}
This study aims to identify the visual aspects and personality of Levi and Mikasa that make it an Idol. The method uses descriptive qualitative analysis, with an approach design to examine each visual aspect of the face, hair, and clothing. It also uses a psychological and cinematographic approach in examining Levi and Mikasa's personality which is displayed through scenes in the movie. The results of this study indicates that the idol figures in the Shingeki no Kyojin movie were chosen based on their personality rather than their visual appearance. The figure who is used as an idol is a character who has a calm, cool personality, can put aside the feelings but still has a sense of caring, not so much talk, strong and strength is recognized by many people, brave and skillful. Visually, idol figures are displayed through color themes that tend to be black, white and gray, as well as the shape of the eyes and lips that have the meaning of strength. Other aspects such as lighting, coloring, shooting size, angle of shooting, and additional lines have an effect on strengthening the personality of the characters displayed in the movie scene.
\end{abstract}

Keywords: representation, idol figure, Shingeki no Kyojin movie, Levi and Mikasa

Abstrak. Penelitian ini bertujuan untuk mengidentifikasi aspek visual dan kepribadian Levi dan Mikasa yang menjadikannya sebagai idola. Metode yang digunakan ialah kualitatif-analisis deskriptif, dengan pendekatan desain untuk mengkaji aspek visual pada bagian wajah, rambut, dan pakaian, serta pendekatan psikologi dan sinematografi yang mengkaji kepribadian tokoh melalui adegan di dalam film. Hasil dari penelitian ini menunjukkan bahwa tokoh idola pada film Shingeki No Kyojin lebih dipilih berdasarkan kepribadiannya daripada tampilan visualnya. Tokoh yang dijadikan idola ialah tokoh yang memiliki kepribadian yang tenang, dingin, dapat mengesampingkan perasaan namun masih memiliki rasa kepedulian, tidak banyak bicara, kuat dan kekuatannya diakui oleh banyak orang, pemberani, dan cekatan. Secara visual tokoh idola ditampilkan melalui tema warna yang cenderung hitam, putih, dan abu, juga bentuk mata dan bibir yang memiliki makna kekuatan. Aspek lain seperti pencahayaan, pewarnaan, ukuran pengambilan gambar, sudut pengambilan gambar, dan garis-garis tambahan berpengaruh dalam memperkuat kepribadian tokoh yang ditampilkan dalam adegan film.

Kata kunci: representasi, tokoh idola, film Shingeki no Kyojin, Levi dan Mikasa

Publisher: Universitas Komputer Indonesia

Copyright: The Author(s) 2018 DOI: 10.34010/artic.2019.4.2448.177-192 


\section{PENDAHULUAN}

Keberadaan film merupakan sebuah bukti sebagai eksistensi dari sebuah budaya [1]. Salah satu negara yang menjadikan film sebagai cerminan dari budayanya ialah Jepang, dimana Jepang banyak memproduksi sebuah film animasi sebagai salah satu bagian dari industri hiburan yang dapat dirasakan keberadaannya sampai saat ini. Animasi secara teknik disebut dengan frame by frame technique, artinya pengambilan shot-nya adalah per gambar [2]. Film yang panjangnya berdurasi 1 detik, harus menyediakan 25 gambar menurut PAL standar Eropa dan Indonesia, dan 30 frame untuk NTSC Standar Jepang dan USA [3]. Film animasi Jepang memiliki gaya unik tersendiri sebagai media sinematografi dan seni bergambar secara tradisional, yaitu kecenderungan mengedepankan kualitas gambar yang menggunakan tangan. Kecenderungan ini bertahan meskipun produk animasi olahan grafis komputer dengan gaya CGI merajalela di Holywood [4]. Maka tidak sedikit, banyak film animasi yang diproduksi dengan mengadaptasi dari manga yang dibuat secara manual. Di antara banyaknya manga yang beredar dan telah diadaptasi menjadi film animasi, ialah Shingeki no Kyojin. Shingeki no Kyojin merupakan sebuah seri manga Jepang yang ditulis dan diilustrasikan oleh Hajime Isayama. diterbitkan pada September 2009 oleh penerbit Kodansha di majalah Bessatsu Shounen dan dianimasikan oleh Wit Studio pada tahun 2013.

Meskipun tetap mempertahankan gaya 2D, film animasi Jepang mengalami perubahan yang signifikan. Jika pada awalnya Katsudo Shashin (1907) yang dianggap sebagai animasi Jepang pertama berwarna hitam putih, dengan teknik stop motion dalam durasi waktu empat detik, Saat ini animasi menjadi berwarna (full color), memakai rata-rata 30 frame gambar per detik, dan dalam durasi sekitar 20-25 menit per episodenya. Perubahan lain yang dirasakan dari film animasi Jepang ialah pada fungsinya. Jika pada awalnya sebagai bagian dari semangat jiwa dalam propaganda perang dunia II, saat ini film animasi merupakan bagian dari industri perfilman yang menyuguhkan berbagai macam genre. Pada prinsipnya fungsi film yang utama yaitu memperoleh hiburan. Akan tetapi dalam film dapat terkandung fungsi informatif maupun edukatif, bahkan persuasif. Tidak sedikit film dapat membawa penontonnya menjadi emosional dan ikut merasakan konflik yang dialami oleh tokoh di dalam film. Maka, tidak heran jika sebuah tokoh animasi diidolakan oleh penontonnya. Dalam sebuah cerita/film ada yang disebut dengan tokoh dan penokohan. Penokohan adalah tampilan penggambaran yang jelas tentang seseorang dalam sebuah cerita. Sedangkan tokoh menunjuk pada orang, atau pelaku cerita [5]. Tokoh idola adalah tokoh yang disenangi, dicintai, disayangi dan dikagumi oleh seseorang berdasarkan kelebihan yang dimilikinya, serta dapat memberikan motivasi yang menjadi perhatian bagi yang mengaguminya [ $[\underline{6}$.

Penelitian terhadap cerita Shingeki no Kyojin sudah dilakukan baik manga (komik) atau film animasinya. Putra dengan pendekatan semiotika John Fiske menganalisis mengenai kelas sosial Karl Marx pada komik Shingeki no Kyojin melalui lima jenis kode kelas sosial Marxisme, kode ukuran gambar sudut pandang gambar, tata cahaya dan dialog, level ideologi kelas sosial Marxisme. Dengan hasil penelitian membuktikan bahwa (1) realitas kelas sosial Marxisme pada manga Shingeki no Kyojin diwakili oleh kode pakaian, berperilaku, berbicara, gestur tubuh, dan ekspresi, (2) representasi dialog pada kaum borjuis dan proletar mengekspresikan ketidakadilan sistem kapitalisme, yang membentuk kelas pekerja dan penguasa, (3) Ideologi kelas-kelas sosial Marxisme diwakili oleh sistem kelas, kapitalisme, komunisme, dan anarkisme [7]. Dari penelitian tersebut menunjukkan bahwa film animasi juga memiliki fungsi untuk menggambarkan realitas kelas sosial menurut teori Karl Marx. Analisis terhadap film yang sama juga dilakukan oleh Marchilah, dengan meneliti mengenai simbol-simbol sosial dan pemaknaan heroisme. Dengan hasil penelitian Simbol heroisme pada film Shingeki no Kyojin dicerminkan dari sisi keberanian, pantang menyerah, rela berkorban, peduli sesama, tidak memandang bulu pada orang yang mereka tolong []. Dari penelitian tersebut

Publisher: Universitas Komputer Indonesia

Copyright: The Author(s) 2018 DOI: 10.34010/artic.2019.4.2448.177-192 
membuktikan bahwa selain mengungkap realitas kelas sosial, film ini juga merepresentasikan heroisme yang dimiliki oleh seorang tokoh. Jika kedua penelitian tersebut berbicara mengenai representasi, penelitian Nasruddin terhadap film animasi Princess Mononoke dan Spirited Away meneliti tentang kepribadian tokoh melalui pendekatan sinematografi dan psikologi. Menjabarkan lima komponen believeability penampilan, motivasi, kepribadian, ekspresi dan relasi berdasarkan isu kemanusiaan yang bersifat sosial dan relevan dengan masa kini [9]. Dari penelitian tersebut dapat disimpulkan bahwa cerita pada film animasi dibangun oleh kepribadian tokohnya ketika menghadapi sebuah masalah.

Dari beberapa penelitian tersebut ada beberapa permasalahan yang menarik untuk diteliti. Misalnya bagaimana kepribadian seorang tokoh dalam film animasi digambarkan ketika sedang menghadapi sebuah masalah. Selain itu, bagaimana perilaku seorang tokoh ketika sedang bersosialisasi antara tokoh yang satu dengan lainnya, dan apakah kepribadian seorang tokoh dapat direpresentasikan selain melalui kostum seperti pada tokoh super hero pada umumnya. Karena pada penelitian sebelumnya tersebut belum ada yang mengkaji mengenai penggambaran kepribadian seorang tokoh film animasi Shingeki no Kyojin menggunakan pendekatan desain, psikologi, dan sinematografi, maka belum dapat diketahui seperti apa representasi kepribadian seorang tokoh digambarkan.

Penelitian ini difokuskan pada tokoh Levi dan Mikasa yang merupakan tokoh idola film animasi Shingeki no Kyojin berdasarkan hasil pemungutan suara pada 133 responden, dengan Levi dan Mikasa memperoleh pemungutan suara sebanyak 28 melebihi Eren dengan perolehan 24 suara. Penelitian mengkaji komposisi bentuk, garis dan warna pada pakaian, fisik, aksesoris. Serta Bahasa Rupa pada adegan dalam frame yang menampilkan kepribadian tokoh. Tujuannya adalah untuk mengetahui representasi yang dihasilkan dari tokoh Levi dan Mikasa melalui tampilan dan kepribadiannya di dalam film sebagai figur idola, mengetahui hubungan antara kepribadian dan desain tokoh dengan representasi yang dihasilkan, mengetahui pengaruh desain terhadap representasi tokoh dalam film animasi, dan mengetahui faktor-faktor penyebab kedua tokoh tersebut populer sebagai figur idola.

\section{METODE}

\subsection{Metode Penelitian}

Metode penelitian yang digunakan ialah kualitatif, analisis-deskriptif. Metode ini menekankan pada makna, penalaran, situasi tertentu dalam kondisi tertentu yang biasanya berhubungan dengan kehidupan sehari hari [10]. Data dari penelitian kualitatif lebih berupa kata-kata daripada angkaangka, data penelitian bersifat deskriptif, yang artinya dapat berupa gejala yang dikategorikan seperti foto, dokumen, artefak, dan catatan [11]. Analisis deskripsi pada penelitian ini untuk mengungkap masalah aktual yang terjadi saat ini pada film animasi Shingeki no Kyojin mengenai peramalan tingkah laku, memberikan gambaran tentang hubungan desain dan psikologi dalam menggambarkan kepribadian tokoh, lalu mengumpulkan, menyusun, menginterpretasikan data yang telah diperoleh, kemudian data dapat disimpulkan sehingga disebut analisa.

\subsection{Proses Analisis}

Beberapa tahapan yang dilakukan pada penelitian ini adalah:

1. Observasi

Pengamatan secara langsung pada Film animasi 2D Shingeki no Kyojin yang mengudara dari tahun 2013-2018, selama tiga musim berjumlah 49 episode.

2. Metode Perekaman 
Video didokumentasikan dengan menggunakan bantuan program FastStone Capture untuk menampilkan gambar sesuai kebutuhan pengamatan

3. Pengumpulan data

Format film sebagai data primer adalah Moving Picture Experts Group-4 disingkat menjadi MPEG4 (.mp4). Melakukan penyebaran kuesioner pada 133 responden dari komunitas Cipanas Atsui Independent yang berasal dari Cipanas dari tanggal 6 September sampai dengan 12 September 2018 sebagai data sekunder.

4. Analisis data

Proses analisis dilakukan dengan menganalisis visual melalui pendekatan desain sebagai pendekatan primer yang memfokuskan pada komposisi bentuk, garis, dan warna visual yang menjadi ciri tokoh Levi dan Mikasa:

1) Pakaian: warna

2) Fisik

Bagian yang lebih mudah dikenali yaitu bagian kepala dan wajah seperti:

Mata: garis, bentuk, dan warna

Bibir: garis dan warna

Rambut: bentuk dan warna

3) Aksesoris sebagai atribut khas dan identitas diri tokoh

Proses analisa selanjutnya ialah dengan menggunakan pendekatan sekunder, yakni pendekatan psikologi dan sinematografi. Untuk mengkaji kepribadian menggunakan pendekatan psikologi paradigma traits Raymond Catell berdasarkan kategori trait:

1) Kategori Kepemilikan (Trait umum-trait khusus)

2) Kategori Kedalaman (Trait permukaan-trait sumber)

3) Kategori Modalias Ekspresi (Trait kemampuan, temperamen, dinamik)

Pendekatan sinematografi menggunakan dua unsur, yaitu unsur naratif dan sinematik dalam film:

1) Unsur naratif

- Cerita dan plot: mendeskripsikan Levi dan Mikasa melalui cerita utama, cerita tambahan dan cerita masa lalu yang saling memiliki keterkaitan.

- Hubungan naratif dengan ruang dan waktu: Sebagai film yang menggunakan pola linear, terdapat kilas balik yang dapat menjadi bahan informasi dalam cerita.

2) Unsur Sinematik

- Kostum dan tata rias karakter: kostum dan tata rias Levi dan Mikasa pada penelitian ini berupa pakaian, dan komposisi wajah.

- Framing: framing sebagai dimensi kamera terhadap objek, ukuran dan sudut pengambilan gambar Levi dan Mikasa ketika berhadapan dengan tokoh tertentu. Pengkajian ini saling berkaitan dengan pendekatan psikologi dan Bahasa Rupa.

5. Bahasa rupa: mendeskripsikan Cara Wimba Levi dan Mikasa dari ukuran pengambilan gambar dan sudut pengambilan gambar, serta Tata Ungkapannya.

6. Reduksi data

Terdapat tiga kategori dalam reduksi data yang dilakukan (1) Kategori A: Jenis film animasi 2D hasil adaptasi dari manga karangan Hajime Isayama, (2) Kategori B: informasi tambahan dari OVA (Original Video Animation) berjudul Attack on Titan: No Regrets (2014) dengan jumlah 2 episode mengenai masa lalu Levi yang sedikit diceritakan di serial film animasinya, (3) Kategori C: meneliti kepribadian Levi dan Mikasa yang berhubungan dengan teori kepribadian Raymond Cattell yang memiliki muatan, adaptasi terhadap masalah, kepribadian dan pembentukannya dan perilaku terhadap tokoh lain.

7. Interpretasi

Publisher: Universitas Komputer Indonesia

Copyright: The Author(s) 2018 DOI: 10.34010/artic.2019.4.2448.177-192 
Memaparkan dengan menerjemahkan kepribadian Levi dan Mikasa melalui adegan dalam film, perbedaan perilaku terhadap tokoh lain yang dikaji melalui Bahasa Rupa, dan representasi yang ditemukan pada opening dan ending film melalui ungkapan berupa realitas.

8. Menarik Kesimpulan

Penarikan kesimpulan sebagai hasil dari penelitian.

\section{HASIL DAN PEMBAHASAN \\ 3.1 Analisis Visual \\ 3.1.1 Visual Levi Ackerman}

1) Rambut

Levi memiliki gaya rambut pendek dengan bagian poni belah menyamping yang cukup panjang hingga sejajar dengan telinga. Rambut Levi berwarna hitam, dan di bagian belakang bawahnya dicukur tipis sehingga panjang rambut bagian atas dan bawah tidak sama. (lihat Gambar 1).

1) Mata

- Warna Mata Levi

Levi memiliki ukuran mata sipit dan ujung yang tajam, memiliki pupil berbentuk lingkaran, berwarna hitam, iris berwarna biru, dan warna di sekitar iris yang juga berwarna hitam (lihat Gambar 2).

- Sudut Mata Levi

Levi memiliki bentuk sudut mata kategori (d) (lihat Gambar $\underline{3}$ dan $\underline{4}$ ), sudut $20^{\circ}$ ke bawah menurut Frutiger (1989) adalah titik tajam yang menghasilkan bahaya, di mana setiap yang melihatnya harus melindungi diri mereka sendiri.

- $\quad$ Iris Mata Levi

Untuk iris mata Levi yang berbentuk lingkaran, menurut Frutiger, untuk manusia primitif lingkaran merupakan simbol yang melambangkan kekuatan karena ada hubungannya dengan matahari, bulan, dan bintang (lihat Gambar 5) [12].

2) Bibir

Jika bentuk bibir dilihat sebagai arah garis, garis bibir Levi termasuk ke dalam kategori bull, memiliki makna hubungan dengan titik agresif panah lurus atau senjata pertahanan, dan juga ada yang mengatakan sebagai api atau lidah (lihat Gambar $\underline{6}$ ) [12].

3) Pakaian

Pakaian pada film Shingeki no Kyojin bukan merupakan penggambaran dari kekuatan yang dimiliki tiap-tiap tokoh, tapi lebih kepada fungsi sebagai pelindung tubuh dan penanda status sosial. Levi masuk ke dalam kategori kaum proletar yang tidak mengenakan baju mewah (lihat Gambar $\underline{7}$ ).

4) Aksesoris

Aksesoris yang menjadi ciri khas Levi adalah cravat yang cenderung selalu ada di bagian lehernya (lihat Gambar $\underline{8}$ ). Cravat juga dinyatakan sebagai fesyen untuk pria yang ingin menunjukkan kekuatan, kekayaan, dan keanggunan [13]. Model cravat yang digunakan oleh Levi adalah model mailcoach berwarna putih (lihat Gambar 9). 


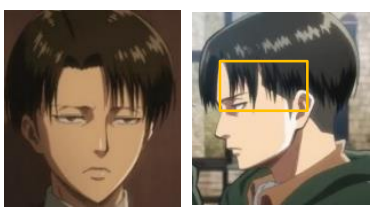

Gambar 1 Rambut Levi

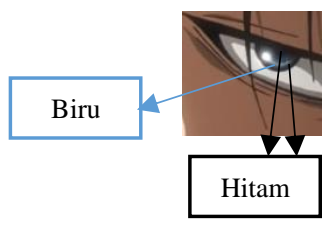

Gambar 2 Warna Mata Levi

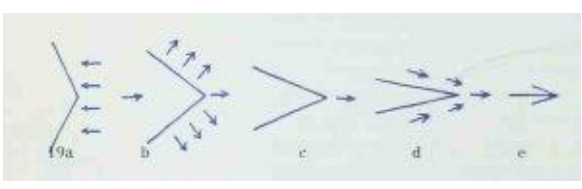

Gambar 3 Kategori Sudut

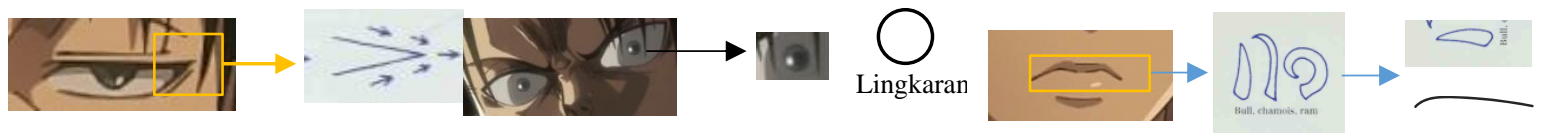

Gambar 4 Sudut Mata Levi

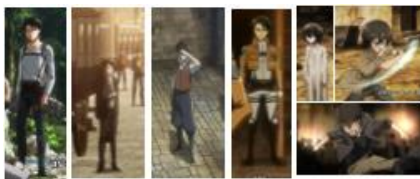

Gambar 7 Pakaian Levi
Gambar 5 Bentuk Iris Mata Levi

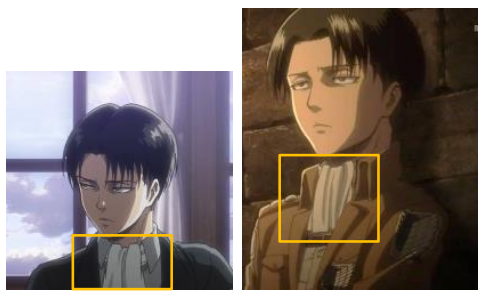

Gambar 8 Cravat Levi
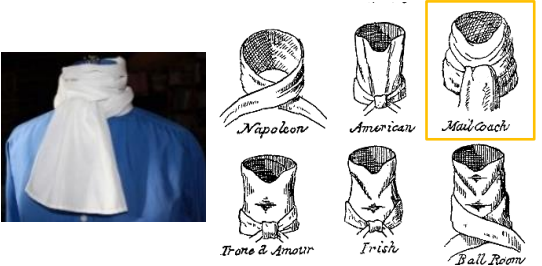

Gambar 9 Model Cravat [13]

Terdapat satu kata kunci yang didapat dari makna sudut mata Levi yang tajam, bibir Levi yang cenderung selalu menekuk ke bawah, dan tujuan orang memakai cravat, yaitu kekuatan. Dari beberapa makna warna yang dimiliki tiap-tiap warna, diambil lima yang mewakili makna visual dari Levi berdasarkan alur cerita dan informasi yang telah di dapatkan, yaitu bahwa Levi; dapat diandalkan (abu), dingin (putih), kuat (hitam), tenang (cokelat). Secara keseluruhan, visual yang ditampilkan oleh Levi memiliki makna kekuatan (lihat Tabel 1).

\begin{tabular}{cll}
\hline No & \multicolumn{1}{c}{ Visual } & \\
\hline 1 & Mata & Sudut: menghasilkan bahaya \\
\cline { 3 - 3 } & & Iris: Kekuatan \\
\hline 2 & Bibir & agresif, bertahan \\
\hline 3 & Cravat & Kekuatan, kekayaan, dan keanggunan \\
\hline 4 & Warna [15] & Mata: tenang (biru) \\
\cline { 3 - 3 } & & Rambut: hitam (kecerdasan) \\
\cline { 3 - 3 } & & Pakaian: dapat diandalkan (abu), dingin (putih), kuat (hitam), tenang (cokelat) \\
\hline
\end{tabular}

Tabel 1 Representasi Levi

\subsubsection{Analisis Visual Mikasa Ackerman}

1) Rambut

Mikasa memiliki rambut berwarna hitam, dengan gaya rambut panjang yang dipotong pendek menjadi model bob (lihat Gambar 10).

2) Mata

- Warma Mata Mikasa 
Mikasa memiliki ukuran mata ukuran sedang dengan sudut yang sedikit tajam. Pupil Mikasa berbentuk oval dan tidak berbentuk lingkaran seperti Levi. Mikasa memiliki pupil warna hitam, iris berwarna abu, dan warna di sekitar iris yang juga berwarna hitam (lihat Gambar $\underline{11}$ ).

\section{- $\quad$ Sudut Mata Mikasa}

Membentuk sudut $\pm 30^{\circ}$, termasuk kategori (c) (Gambar 3), sudut yang dapat dibandingkan dengan bajak bumi (earth plough). Memiliki sinonim plow; berarti membajak, menyeruduk, jika digunakan dalam mesin kata ini memiliki arti bergerak dengan cepat dan tidak terkendali (lihat Gambar 12) [14]. - Iris Mata Mikasa

Adapun bentuk anekdot oval, biasa digunakan oleh seniman dalam menggambarkan mobil balap, membentuk roda yang miring untuk menekankan ide kecepatan (lihat Gambar 13) [12].

3) Bibir

Sama seperti Levi, Mikasa memiliki bentuk bibir bull yang berarti menekuk, dan bermakna memiliki sifat agresif atau bertahan (lihat Gambar 14) [12].

4) Pakaian

Mikasa mengenakan tiga model pakaian ketika masih anak-anak. Saat ini, Mikasa cenderung selalu mengenakan kemeja sebagai atasan, dengan bawahan rok yang berganti warna dan sesekali mengenakan celana. Mikasa masuk ke dalam kategori kaum proletar sama seperti Levi (lihat Gambar 16).

5) Aksesoris

Syal berwarna merah dengan ujung merumbai menjadi salah satu ciri khas Mikasa, karena syal tersebut selalu dikenakannya dari mulai Mikasa tinggal bersama Eren, sampai saat ini. Itu berarti Mikasa benar-benar menjaga syal pemberian Eren tersebut (lihat Gambar 17).

Dari beberapa kategori tersebut didapatkan tiga kata kunci yang direpresentasikan oleh Mikasa, yaitu; cepat, kuat, perasaan. Berdasarkan hal tersebut dapat disimpulkan Mikasa merupakan tokoh yang memiliki, memiliki kekuatan, kecepatan dalam satu atau beberapa hal, dan juga memiliki perasaan yang ditunjukkan melalui cinta, dan persahabatan lihat Tabel 2).

\begin{tabular}{cll}
\hline No & \multicolumn{1}{c}{ Visual } & \\
\hline 1 & Mata & Sudut: bergerak cepat, tidak terkendali \\
\cline { 3 - 3 } & & Iris: ide kecepatan \\
\hline 2 & Bibir & Agresif, bertahan \\
\hline 3 & Warna [15] & Mata: emosi yang kuat (abu) \\
\cline { 3 - 3 } & & Rambut: hitam (kecerdasan) \\
\cline { 3 - 3 } & & $\begin{array}{l}\text { Pakaian: dapat diandalkan (abu), dingin (putih), kuat (hitam), roman (merah), } \\
\text { agresi (jingga), persahabatan (kuning) }\end{array}$ \\
\cline { 3 - 3 } & & Syal: cinta (merah) \\
\hline
\end{tabular}

Tabel 2 Representasi Mikasa

Publisher: Universitas Komputer Indonesia

Copyright: The Author(s) 2018 DOI: 10.34010/artic.2019.4.2448.177-192 


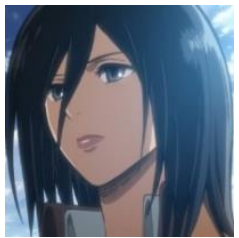

Gambar 10 Rambut Mikasa

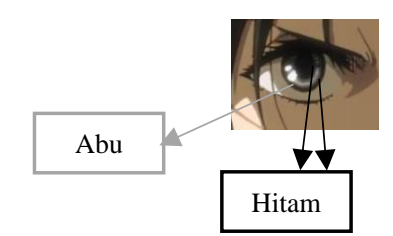

Gambar 11 Warna Mata Mikasa

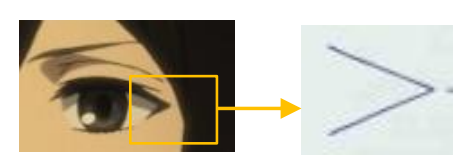

Gambar 12 Sudut Mata Mikasa

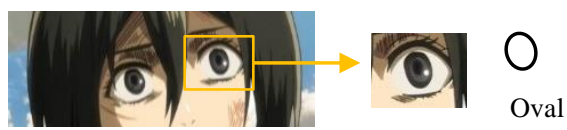

Gambar 13 Iris Mata Mikasa

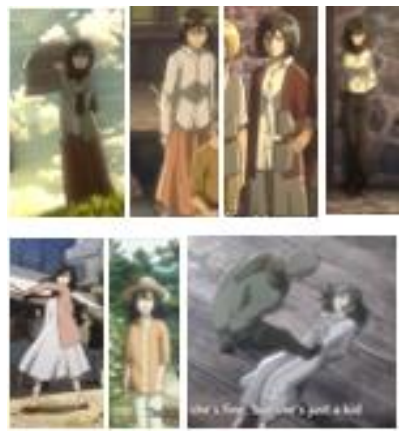

Gambar 15 Pakaian Mikasa

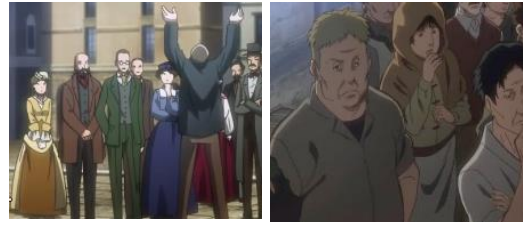

Gambar 16 Kaum borjuis (a), proletar (b)

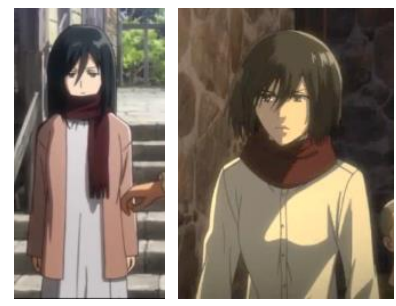

Gambar 17 Syal Mikasa

\subsubsection{Frekuensi Penampilan}

Hasil perhitungan terhadap tokoh Eren, Levi dan Mikasa dari total 49 episode ialah: Eren muncul 47 episode dari 49 episode. Meski pada beberapa episode Sementara Mikasa dimunculkan dalam 45 episode meski dalam beberapa episode hanya pada scene yang sedikit. Sedangkan Levi hanya dimunculkan sebanyak 30 episode, itu pun dalam beberapa episode hanya dimunculkan satu scene saja. Jika dibandingkan dengan ketiganya, Levi adalah tokoh yang kemunculannya paling sedikit. Tetapi memperoleh hasil pemungutan suara paling banyak. Dari data tersebut, ini membuktikan bahwa frekuensi penampilan pada film animasi Shingeki no Kyojin tidak mempengaruhi tingkat kepopuleran tokoh.

\subsubsection{Representasi pada opening dan ending film}

Gambar $\underline{18}, \underline{19}$, dan $\underline{20}$ merupakan salah satu adegan yang dapat mewakili pembahasan pada penelitian ini, ialah cuplikan adegan pada opening dan ending film yang menampilkan Levi dan Mikasa dan analisis makna-maknanya dapat dilihat pada Tabel $\underline{3}$. 


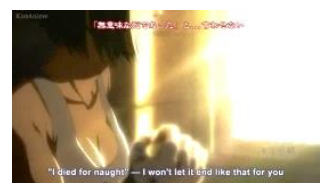

Gambar 18 Kemunculan Levi pada Opening

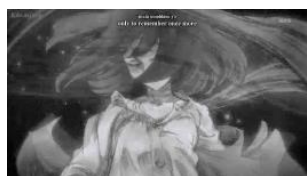

Gambar 20 Kemunculan Mikasa pada Ending

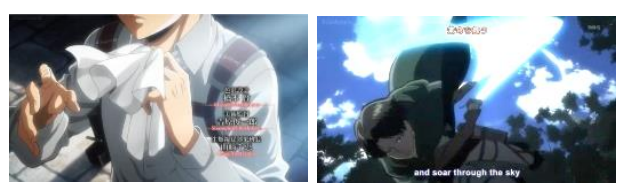

Gambar 19 Kemunculan Mikasa pada Opening

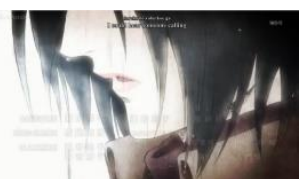

Tabel 3 Representasi

\begin{tabular}{|c|c|c|}
\hline \multicolumn{3}{|c|}{ Opening } \\
\hline Musim/Eps & Levi & Mikasa \\
\hline \multirow{2}{*}{$\begin{array}{c}\text { Musim 1 (I) } \\
\text { Eps 1-13 }\end{array}$} & \multirow{2}{*}{$\mathrm{x}$} & Kekuatan \\
\hline & & Perhatian (pada Eren) \\
\hline \multirow{2}{*}{$\begin{array}{l}\text { Musim } 1 \text { (II) } \\
\text { Eps 14-25 }\end{array}$} & Kekuatan & Kekuatan \\
\hline & Aktivitas rutin & Aktivitas rutin \\
\hline \multirow{2}{*}{$\begin{array}{c}\text { Musim } 2 \\
\text { Eps 28-37 }\end{array}$} & Ciri khas (atribut) & Ciri khas (atribut) \\
\hline & Ciri khas (menggunakan pedang) & Keberanian, Cekatan, Kekuatan \\
\hline $\begin{array}{c}\text { Musim } 3 \\
\text { Eps } 38-49\end{array}$ & Kemampuan khusus & Perubahan Kepribadian \\
\hline \multicolumn{3}{|c|}{ Ending } \\
\hline Musim/Eps & Levi & Mikasa \\
\hline \multirow{3}{*}{$\begin{array}{l}\text { Musim 1 (I) } \\
\text { Eps 1-13 }\end{array}$} & \multirow{3}{*}{$\mathrm{x}$} & Perubahan fisik (pertumbuhan usia) \\
\hline & & Perubahan visual (gaya rambut dan pakaian) \\
\hline & & Perubahan perilaku (Keberanian) \\
\hline \multirow{2}{*}{$\begin{array}{c}\text { Musim } 1 \text { (II) } \\
\text { Eps 14-24 }\end{array}$} & \multirow[t]{2}{*}{$\mathrm{x}$} & Pendiam \\
\hline & & Memiliki sisi lemah (Menyangkut Eren) \\
\hline Musim 2 & $\mathrm{x}$ & $\mathrm{x}$ \\
\hline Musim 3 & $\mathrm{x}$ & $\mathrm{x}$ \\
\hline
\end{tabular}

\subsection{Analisis Kepribadian Levi dan Mikasa \\ 3.2.1 Bahasa Rupa Kepribadian Levi}

Terdapat 19 trait yang ditemukan pada kepribadian Levi:

1) Kategori Kepemilikan

a) Trait Umum: kecemasan

b) Trait Khusus (Ketertarikan): cinta kebersihan

c) Trait Khusus (Perilaku): kejam, tegas, peduli anak buah, kasar

2) Kategori Kedalaman

a) Trait Permukaan: dingin, pemarah, pendiam 
b) Trait Sumber: kejam, kuat

3) Kategori Modalitas Ekspresi

a) Trait Kemampuan: cermat, cerdas, cekatan, mengesampingkan perasaan

b) Trait Temperamen: tenang, berpikir dengan kepala dingin, Berani

Gambar 21 berikut merupakan salah satu contoh kepribadian Levi yang ditampilkan melalui adegan dalam film yang dibedah dengan menggunakan keilmuan sinematografi dan Bahasa Rupa.
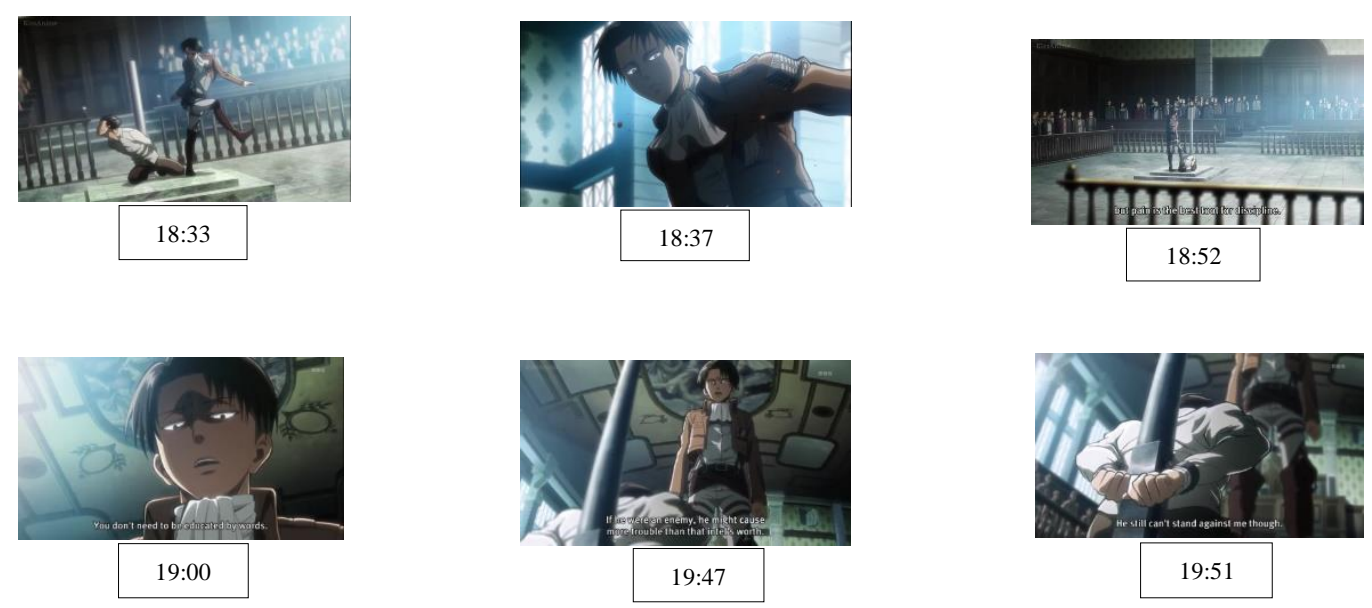

Gambar 21 Cuplikan adegan Trait Khusus (Perilaku) Levi: Kejam

Sifat kejam Levi ditunjukkan melalui adegan ketika menghajar Eren tanpa henti dengan ekspresi muka yang biasa. Levi melakukannya tanpa ragu di tengah ruang sidang, di depan beberapa orang yang memiliki kedudukan lebih tinggi dari Levi. Levi diposisikan membelakangi cahaya, sehingga ketika Levi diambil dari sudut bawah, bagian depan tubuh Levi terlihat gelap. Low Angle mampu memberi kesan lebih besar (raksasa) pada sebuah objek, dominan, percaya diri, serta kuat [16]. Bahasa Rupa kepribadian Levi pada trait kejam ialah:

a) Cara Wimba: close up, medium close up, Sudut bawah

b) Tata Ungkap: alih pengambilan, alih depth of field

- Keterangan: Frame bergeser dari atas, semula memperlihatkan dan lebih memfokuskan Wimba Levi, kemudian bergeser ke bawah beralih fokus ke Wimba Eren

c) Elemen Visual

- Cahaya: gelap pada bagian depan tubuh

- Warna: putih, putih kebiruan

- Warna putih pada bola mata terlihat terang

d) Gaya bicara: Intonasi biasa

e) Posisi: Berhadapan dengan lawan bicara, berada di atas frame

\subsubsection{Bahasa Rupa Kepribadian Mikasa}

Terdapat 14 trait yang ditemukan pada kepribadian Mikasa:

1) Kategori Kepemilikan

d) Trait Umum: kecemasan 
e) Trait Khusus (Ketertarikan): Protektif (pada Eren)

f) Trait Khusus (Perilaku): gegabah, ceroboh, egois, peduli sesama, setia kawan

2) Kategori Kedalaman

c) Trait Permukaan: dingin, pendiam

d) Trait Sumber: kuat

3) Kategori Modalitas Ekspresi

c) Trait Kemampuan: cekatan, mengesampingkan perasaan, fokus tujuan,

d) Trait Temperamen: tenang, berani

Gambar 22 merupakan salah satu contoh kepribadian Mikasa berupa trait egois yang hanya muncul jika ada kaitannya dengan keselamatan Eren.
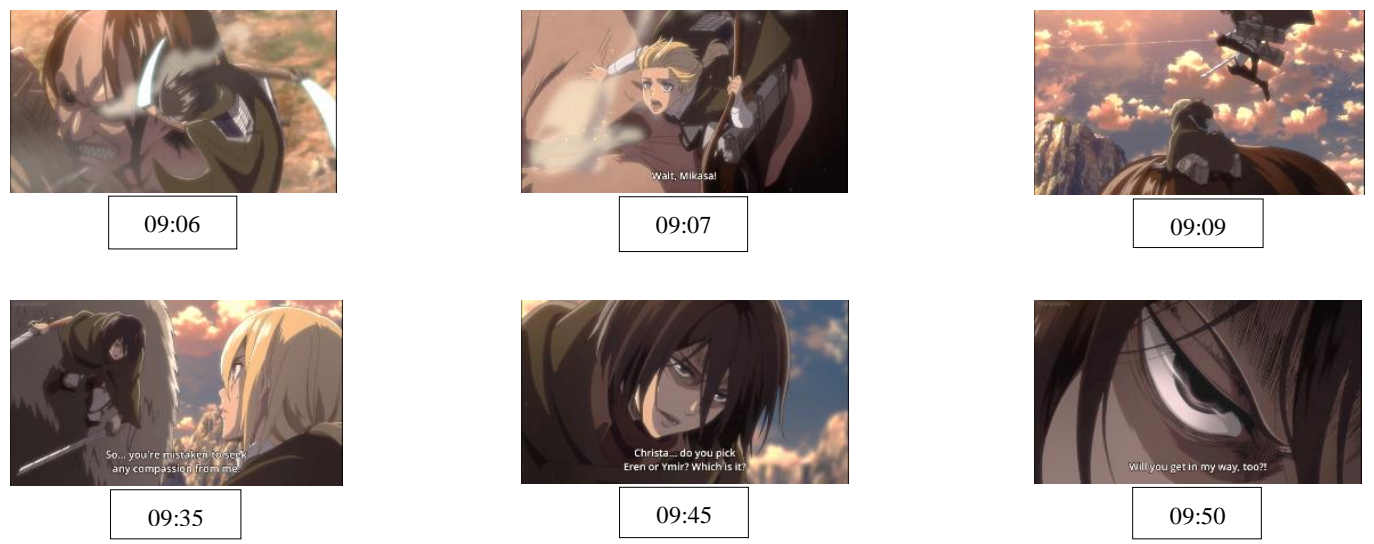

Gambar 22 Cuplikan adegan Trait Khusus (Perilaku) Mikasa: egois

Keegoisan Mikasa terlihat ketika dirinya secara tidak langsung memaksakan keinginannya pada Historia untuk memilih Eren, dan membiarkan Mikasa membunuh Ymir, temannya Historia, jika menghalangi jalan untuk menyelamatkan Eren. Bahasa Rupa kepribadian Mikasa pada trait ini ialah:

a) Cara Wimba: close up, ekstra close Up, sudut wajar, sudut bawah

b) Tata Ungkap: garis-garis tambahan

- Keterangan: garis-garis tambahan pada sekitar mata dan kening Wimba Mikasa. Untuk memperkuat ekspresi pada Wimba Mikasa

c) Elemen Visual

- Cahaya: gelap pada bagian kening dan mata

- Warna: jingga

d) Gaya bicara: intonasi naik

e) Posisi: berhadapan dengan lawan bicara

\subsection{Analisis Bahasa Rupa pada Perilaku Levi dan Mikasa}

Analisis Bahasa Rupa menitikberatkan pada perilaku Levi dan Mikasa kepada tokoh lain (lihat Gambar 23). 


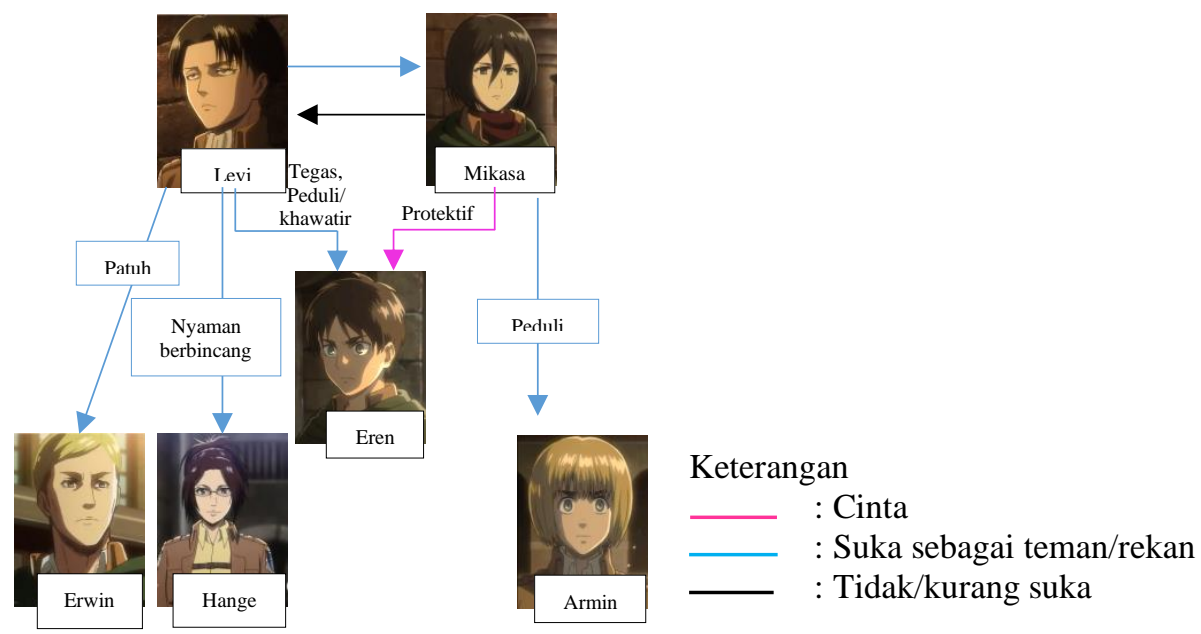

Gambar 23 Diagram Perilaku

\subsubsection{Perilaku Levi pada tokoh lain}

Bahasa Rupa perilaku peduli/khawatir Wimba Levi pada Eren ialah dengan posisi Berada lebih tinggi dari Eren, berada di depan Eren, tidak menoleh ke atas (pada Hange) yang berdiri di sampingnya (lihat Gambar 24).

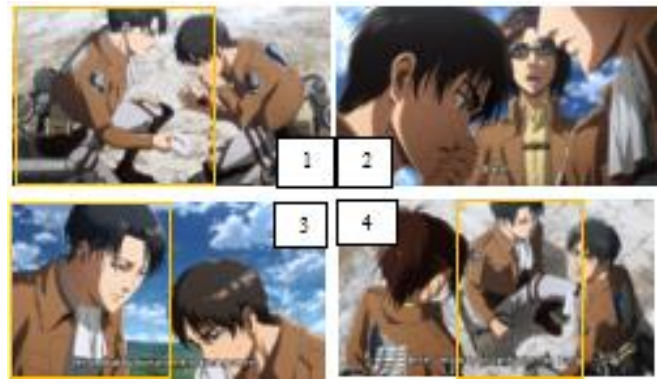

Gambar 24 Perilaku Levi

\begin{tabular}{|c|l|l|}
\hline No & \multicolumn{1}{|c|}{$\begin{array}{c}\text { Ukuran } \\
\text { Pengambilan }\end{array}$} & $\begin{array}{c}\text { Sudut } \\
\text { Pengambilan }\end{array}$ \\
\hline 1. & Medium Shot & Sudut atas \\
\hline 2. & Very Close up & Sudut wajar \\
\hline 3. & Close Up & Sudut wajar \\
\hline 4. & Medium Shot & Sudut atas \\
\hline
\end{tabular}

Tabel 4 Bahasa Rupa (Cara Wimba) Levi

Cara Wimba sudut pengambilan pada tokoh Levi cenderung menggunakan sudut wajar dan sudut bawah. Sudut bawah sebagai bidikan point of view menyiratkan bahwa orang yang berada pada pengamatan sudut bawah itu lebih kecil, lebih lemah, atau dalam posisi kompromistis [17]. Sehingga pemirsa sebagai orang yang melakukan pengamatan dari sudut tersebut merasa Levi lebih kuat dan lebih besar. Sudut bawah juga memberikan kesan dominan, percaya diri, serta kuat pada trait kejam Levi.

Pada beberapa penggambaran yang melibatkan interaksi antara Levi dengan satu atau dua lawan bicara, Levi terlihat berada di atas frame, yaitu Levi berada di bagian atas dari pembagian satu pertiga pada frame (lihat Gambar 25). Objek pada bagian atas bingkai menerima lebih banyak perhatian karena lebih memiliki 'berat' [17]. Jadi, Levi merupakan tokoh yang dianggap penting karena keberadaannya lebih 'berat' daripada tokoh lain. 


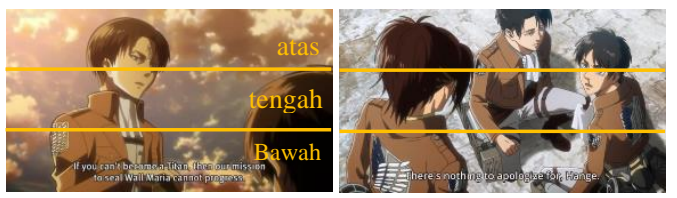

Gambar 25 Levi di atas Frame

\subsubsection{Perilaku Levi pada tokoh Mikasa}

Bahasa Rupa perilaku peduli Wimba Mikasa pada Armin ialah dengan posisi berada di belakang Armin dan berada di atas frame (lihat Gambar 26).

Cara Wimba sudut pengambilan pada tokoh Mikasa cenderung menggunakan sudut wajar. Sudut wajar atau Vertical Camera Angle adalah posisi kamera yang sejajar horizontal pada mata objek [17] Posisi ini dapat membuat pemirsa dapat menghubungkan atau merasakan hal yang sama dengan tokoh yang ada di dalamnya (lihat Tabel 5).
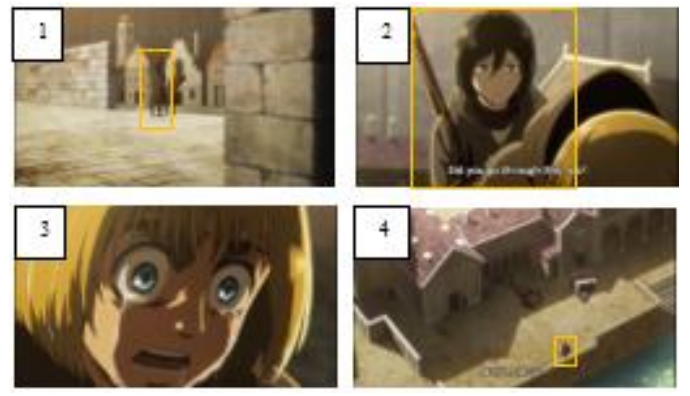

Gambar 26 Perilaku Mikasa

\begin{tabular}{|c|l|l}
\hline No & \multicolumn{1}{|c|}{$\begin{array}{c}\text { Ukuran } \\
\text { Pengambilan }\end{array}$} & \multicolumn{1}{|c}{$\begin{array}{c}\text { Sudut } \\
\text { Pengambilan }\end{array}$} \\
\hline 1. & Long Shot & Sudut wajar \\
\hline 2. & Midshot & Sudut wajar \\
\hline 3. & Big Close Up & Sudut wajar \\
\hline 4. & Ekstra long shot & $\begin{array}{l}\text { Sudut tampak } \\
\text { burung }\end{array}$ \\
\hline
\end{tabular}

Tabel 5 Bahasa Rupa (Cara Wimba) Mikasa

Mikasa cenderung memberikan kesan pada pemirsa sebagai tokoh yang posisinya sama dengan pengamatnya (baik pemirsa atau lawan bicaranya dalam adegan), tidak lebih kuat atau lebih lemah (lihat Gambar 27).

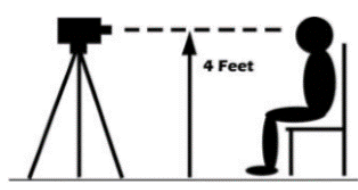

Gambar 27 Vertical Camera Angle

\section{KESIMPULAN DAN SARAN}

Beberapa kesimpulan dari analisis Levi dan Mikasa berdasarkan visual dan kepribadiannya dijabarkan melalui beberapa poin sebagai berikut:

1. Representasi Levi dan Mikasa dikategorikan menjadi dua, yaitu melalui visual dan melalui kepribadiannya.

a) Melalui Visual 
- Representasi yang dihasilkan oleh Levi adalah kekuatan (Tabel 1) sementara Mikasa adalah cinta, kuat, dan perasaan (Tabel 2).

- Levi dan Mikasa memiliki kesamaan tema warna, yakni hitam, putih, dan abu, serta aspek visual yang ada pada tokoh merupakan representasi yang sesuai dengan kepribadiannya yang diceritakan di dalam film

b) Kepribadian

- Levi memiliki kedudukan dan kepribadian yang lebih kuat dari Mikasa

- Kepribadian yang sama-sama dimiliki oleh kedua tokoh ialah sikap yang tenang, dingin, mengesampingkan perasaan, peduli terhadap sesama, pendiam, kuat, pemberani, cekatan, dan memiliki ciri maskulin.

2. Dalam film animasi Shingeki no Kyojin, tokoh idola lebih dipilih melalui kepribadiannya daripada visualnya, dibuktikan melalui:

a) Perbandingan hasil pemungutan suara

b) Frekuensi Penampilan

3. Desain memberikan pengaruh dalam menampilkan kepribadian Levi dan Mikasa melalui adegan di dalam film. Beberapa unsur desain yang berpengaruh yaitu:

a) Warna

Warna pada latar memberikan pengaruh dalam menampilkan kepribadian tokoh pada adegan, sebagai penciptaan suasana, atau mood, yang dapat memperkuat kepribadian tokoh. Warna latar yang digunakan ialah mengikuti warna waktu atau cuaca seperti (1) cerah: putih, (2) sore/dalam ruangan menggunakan lampu minyak: jingga, (3) siang/siang menuju sore: kuning, (4) mendung: abu.

b) Garis-garis

Pada trait kecemasan, terdapat perbedaan dalam penggambaran garis-garis antara Levi dan Mikasa. Garis-garis tambahan yang terdapat di wajah kedua tokoh ditunjukkan ketika kedua tokoh tersebut mengalami gejolak emosi. Garis-garis tambahan dan ekspresif digunakan ketika menggambarkan tokoh Levi dan Mikasa yang sedang melakukan aktivitas dan menunjukkan kemampuan ketika melakukannya.

4. Penggunaan unsur Bahasa Rupa dan desain seperti warna, bentuk, garis, dalam menampilkan kepribadian tokoh Levi dan Mikasa pada setiap adegan di film cenderung berbeda. Ini menunjukkan bahwa setiap tokoh merupakan karakter unik, yang dapat membentuk suatu cerita dengan kepribadian yang dikuatkan melalui unsur-unsur tersebut.

5. Film animasi Shingeki no Kyojin merupakan film yang lebih menekankan pada cerita. Misalnya, untuk melambangkan kekuatan pada seorang tokoh, ditampilkan melalui adegan ketika tokoh tertentu menghadapi musuh, melalui data statistik yang disampaikan langsung oleh Hajime Isayama dalam bukunya, dan melalui penceritaan langsung di dalam film, bukan dari kostum atau perubahannya dan bukan dari bentuk tubuh, misalnya badan yang besar dan memiliki otot.

6. Bahasa Rupa Cara Wimba seperti ukuran pengambilan dan sudut pengambilan berpengaruh dalam menampilkan kepribadian dan memperkuat perilaku Levi dan Mikasa ketika berinteraksi dengan tokoh lain.

7. Dilihat dari banyaknya ukuran pengambilan gambar secara Close Up, film animasi Shingeki no Kyojin menggunakan Bahasa Rupa modern Barat, karena lebih menampilkan tampilan wajah (ekspresi) dengan penggambaran Close Up daripada sikap tubuh (gesture) dengan penggambaran dari kepala sampai kaki.

8. Shingeki no Kyojin bukan berlatar di negara Jepang, melainkan pada suatu tempat yang penduduknya terdiri dari berbagai negara dan berbagai ras berkumpul dalam sebuah tempat dilindungi Wall, kemudian melahirkan keturunan yang beragam yang dapat dilihat di dalam film. Levi Ackerman meski merupakan satu garis keturunan dengan Mikasa Ackerman, tetapi memiliki mata sipit berwarna 
biru, karena bukan merupakan keturunan ras Asia seperti Mikasa yang cenderung bermata gelap. Tidak heran dijumpai banyak karakter yang memiliki visual seperti wajah orang Eropa.

Berdasarkan penelitian yang telah dilakukan, beberapa saran yang dapat diajukan antara lain:

1. Dalam membuat sebuah film animasi, plot cerita sebaiknya dirancang bersamaan dengan perancangan tokoh yang akan memerankannya. Perancangan tersebut sebaiknya tidak berfokus hanya pada aspek visualnya saja, melainkan pada aspek biografi dan kepribadiannya. Sehingga 'karakter' seorang tokoh tidak mudah berubah begitu saja di tengah-tengah cerita karena adanya suatu kejadian tertentu. Melainkan dengan kejadian tertentu, karakter tokoh dapat diperkuat dari bagaimana dirinya menghadapi serta menyelesaikan sebuah masalah. Namun jika memang perubahan karakter itu terjadi, seorang desainer dapat memberikan alasannya melalui sebab akibat dari sebuah penceritaan di dalam film.

2. Sebaiknya para desainer di Indonesia, khususnya yang terjun dalam industri film animasi, desain tokoh tidak mengikuti gaya gambar dari film animasi Jepang seperti kecenderungan komik Indonesia yang gaya gambarnya mengikuti Jepang. Hal ini dimaksudkan agar para desainer dapat lebih bebas mengekspresikan kreativitasnya, tanpa harus berpikir bahwa gaya gambar dari Jepang merupakan aturan baku yang perlu diikuti dalam membuat sebuah komik atau film.

3. Penelitian dapat dilanjutkan dengan metode yang mengarah pada Bahasa Rupa film pada satu episode atau pembuka dan penutup filmnya saja, agar didapatkan data mengenai unsur Bahasa Rupa yang dimiliki secara lebih jelas dan spesifik.

\section{UCAPAN TERIMAKASIH}

Puji syukur kepada Allah SWT, karena dengan rahmat dan karunia-Nya, penulis dapat menyelesaikan karya Ilmiah berjudul "Representasi idola film animasi Shingeki no kyojin". Pada tokoh Levi dan Mikasa. Dalam penyusunan penelitian ini, peneliti tidak terlepas dari dukungan dan bantuan berbagai pihak. Oleh karena itu penulis mengucapkan rasa terima kasih kepada para dosen, keluarga, teman, dan pihak yang terlibat atas arahan dan masukannya. Sehingga penyusunan ini dapat diselesaikan.

\section{DAFTAR PUSTAKA}

[1] Mabruri, Anton. (2013). "Panduan Penulisan Naskah TV: Format Acara Drama.” Jakarta: PT.Grasindo.

[2] Maulana, Achmad Fadli. (2013).“Perancangan Komunikasi Visual Film Animasi Dokumenter 'Kamikaza: Kesatuan Udara Bunuh Diri Jepang'.” S1 Thesis. Universitas Bina Nusantara.

[3] Gumelar, M. S. (2004). "Memproduksi Animasi TV: Solusi Murah dan Cepat." An1mage.

[4] Cavallaro, Dani. (2007). "Anime Intersections: Tradition and Innovation in Theme and Technique." McFarland Publishing.

[5] Nurgiyantoro, Burhan. (2018). "Teori Pengkajian Fiksi.” UGM press.

[6] Gafar, A. (2014). "Kemampuan Menceritakan Tokoh Idola dengan Media Gambar." Pena: Jurnal Pendidikan Bahasa dan Sastra, 3(2).

[7] Nuraeni, R., \& Maulana, S. (2015). "Presentasi Pemikiran Marxisme Pada Manga (studi Semiotika John Fiske Mengenai Kelas Sosial Karl Marx Pada Komik Shingeki No Kyojin).” eProceedings of Management, 2(3).

[8] Marchliah, Tika. (2014). "Representasi Makna Heroisme dalam Film Kartun (Analisis Semiotika Film Kartun Shingeki No Kyojin Episode 8, 21 Dan 25)." S1 Thesis, Universitas Mercu Buana. 
[9] Nasruddin, Merlina Fatimah. (2016). "Komponen Believability pada Karakter Protagonis dan Antagonis Film Miyazaki (Princess Mononoke, Spirited Away).” Undergraduated Thesis, Universitas Komputer Indonesia.

[10] Sarwono, Jonathan. (2006). "Metode Penelitian Kuantitatif dan Kualitatif." Yogyakarta: Graha Ilmu.

[11] Rohidi, Tjetjep Rohendi. (2011). "Metodologi Penelitian Seni." Semarang: Cipta Prima Nusantara.

[12] Frutiger, Adrian. (1989). "Signs and Symbols." New York: Van Nostrand Reinhold.

[13] Schneider, Sven Raphael. (2016). "The Evolution of Neckwear - From Scarf To Tie \& Why We Wear Ties Today." Diambil dari: https://www.gentlemansgazette.com/evolutionneckwear-tie-cravat-scarf/ (diakses pada 03 Januari 2019).

[14] _. (2019). "Plough." Diambil dari: https://en.oxforddictionaries.com/definition/plough (diakses pada 03 Januari 2019).

[15] Rustan, Surianto. (2009). "Mendesain Logo.” Jakarta: PT.Gramedia Pustaka Utama.

[16] Pratista, Himawan. (2017). "Memahami Film." Yogyakarta: Montase Press.

[17] Thompson, R., \& Bowen, C. J. (2009). "Grammar of the Shot.” Taylor \& Francis. 